\title{
Asthenospheric channeling of the Icelandic upwelling: Evidence from seismic anisotropy
}

\author{
Mei Xue*,1, Richard M. Allen ${ }^{1}$ \\ Department of Geology and Geophysics, University of Wisconsin-Madison, 1215 West Dayton Street, Madison, WI 53706, USA
}

Received 15 June 2004; received in revised form 17 March 2005; accepted 20 March 2005

Available online 19 May 2005

Editor: R.D. van der Hilst

\begin{abstract}
Two end-member geometries, radial flow and ridge-channeled flow, have been proposed for the dispersion of material upwelling beneath Iceland. Seismic anisotropy provides information on mantle flow, and therefore has the potential to discriminate these two geometries. In this study, we combine the HOTSPOT and SIL datasets (39 stations) and select 28 events for teleseismic shear-wave splitting analysis. Splitting results in central and eastern Iceland show 1-2 s splitting times with an average NNW-SSE orientation of the fast splitting direction and an anti-clockwise rotation of fast axes from east to central Iceland. In western Iceland, smaller splits with more $\mathrm{N}-\mathrm{S}$ orientations are observed. Since crustal splitting times in Iceland are 0.1 $\mathrm{s}$ to $0.3 \mathrm{~s}$, our delays of up to $2 \mathrm{~s}$ indicate a mantle source. Both the lack of dependence of the splitting parameters on event back azimuth and the observations of null splits for events where the back azimuth is parallel or perpendicular to the fast splitting directions (observed using other events) suggest that one layer of anisotropy dominates beneath Iceland. While both high stress plus enriched water content and melt-rich layers can result in a $90^{\circ}$ rotation of the fast splitting direction with respect to the flow direction, we interpret our fast axis orientation as pointing in the direction of flow as the magnitude of stress is low and the amount and geographical extent of melt are likely small beneath Iceland. The observed anisotropy pattern beneath Iceland is inconsistent with radial flow away from the upwelling. Instead we propose a ridge-channeled flow model in which there is horizontal flow of material away from the upwelling axis beneath southeast Iceland toward the southern end of the Kolbeinsey Ridge and the northern end of the Reykjanes Ridge, both of which are west of the upwelling. This geometry is similar to the ridge perpendicular flow predicted for off-ridge hotspots towards the ridge. We hypothesize that upwelled material then feeds ridge parallel asthenospheric channels beneath the North Atlantic Ridge. Our interpretation is thus consistent with generation of Vshaped ridges by channeling of upwelling material down the Reykjanes and Kolbeinsey ridges.
\end{abstract}

(C) 2005 Elsevier B.V. All rights reserved.

Keywords: Iceland; mantle upwelling; seismic anisotropy; shear-wave splitting; asthenospheric channeling

\footnotetext{
* Corresponding author. Tel.: +1 5106435450 .

E-mail address: meixue@seismo.berkeley.edu (M. Xue).

${ }^{1}$ Present address: Department of Earth and Planetary Science, University of California Berkeley, 215 McCone Hall, Berkeley CA 94720, USA.
}

0012-821X/\$ - see front matter (C) 2005 Elsevier B.V. All rights reserved.

doi:10.1016/j.eps1.2005.03.017 


\section{Introduction}

Iceland is a hotspot located on the North Atlantic Ridge, with the Reykjanes Ridge to the south and the Kolbeinsey Ridge to the north. This special location makes Iceland an ideal place to study the interactions between hotspot upwelling and mid-ocean ridge processes. Seismic studies show the presence of a low velocity anomaly extending vertically through the upper mantle, which has been interpreted as a high temperature buoyant upwelling centered beneath southeast Iceland [1-4]. Surface observations such as the broad high topography of the Reykjanes Ridge, which is much smoother and lacks the segmentation of typical slow-spreading ridges [5,6], and the thicker crust of Iceland up to six times that of normal oceanic crust $[7,8]$ also suggest that the uppermost mantle is relatively high temperature producing large volumes of melt. This influence of the Iceland upwelling extends down the Kolbeinsey and Reykjanes ridges to the north and south of Iceland. A Vshaped pattern of bathymetry and gravity anomalies, interpreted as representing the passage of melting anomalies along the ridge away from Iceland, is observed along both the Reykjanes Ridge $[9,10]$ and on the eastern side of the Kolbeinsey Ridge (the lack of symmetry of the western side is probably due to the fact that the V-shaped ridge gravity signal has been attenuated by the gravity signal caused by up to $4 \mathrm{~km}$ of overlying sediments shed from Greenland [11]). Geochemical signatures show that both the Reykjanes Ridge and the Kolbeinsey Ridge are affected by the Iceland upwelling [12-14]. The Kolbeinsey Ridge is less affected than the Reykjanes Ridge, and might be modified by upwelling beneath Jan Mayen in addition to Iceland [13-15]. All these observations are generally taken as indicators of the existence and spatial influence of the Icelandic upwelling. While they are consistent with a whole-mantle plume, global tomography studies do not support the continuation of the upper mantle low velocity anomaly down into the lower mantle [16-18]. We therefore use the term "upwelling" instead of "plume".

Various models have been proposed for the interaction between the Icelandic upwelling and the North Atlantic Ridge based on the above observations, via either along-axis melt transport $[19,20]$ or large-scale asthenospheric flow [21-26]. Estimates of upwelling flux and crustal generation rates imply that the bulk of upwelling material flows away from the region without participating in melting processes beneath Iceland [1]. A key question is how does this upwelling material disperse in the North Atlantic asthenosphere? This remains enigmatic not only to Iceland, but to other plume-ridge systems [27]. Two geometries have been suggested: radial flow and ridge-channeled flow. Vogt [10] first discussed both radial and channeled flow and subsequent studies have generally supported one of these two end-member models. In radial flow, material spreads out in all directions away from the upwelling axis $[25,28,29]$, whereas in channeled flow, upwelling material feeds asthenospheric channels below the spreading axis [19,21-23,26].

New constraints are needed to test and distinguish between these two geometries. Seismic anisotropy provides information about mantle strain; constraints on anisotropic structure beneath Iceland therefore have the potential to elucidate mantle flow geometries in the region. In previous anisotropy studies [30,31], the splitting observations in Iceland fall into two groups: in eastern Iceland the average splitting direction is NNW-SSE, and in western Iceland the average splitting direction is rotated clockwise to $\mathrm{N}-\mathrm{S}$ [31] or NNE-SSW [30]. Bjarnason et al. [30] interpret their teleseismic shear-wave splitting results as the consequence of shear between the North American or Eurasian plate and background mantle flow, concluding that mantle flow is in a northward direction. $\mathrm{Li}$ and Detrick [31] also interpret their shear-wave splits as being the result of background mantle flow. In addition, they constrain anisotropy using Rayleigh waves and conclude there are two layers of anisotropy above $100 \mathrm{~km}$ in western and central Iceland, and SKS splitting is primarily caused by flow deeper than 100 $\mathrm{km}$. This interpretation reconciles the departure of their surface wave results from splitting results and also implies that the Iceland upwelling and its interaction with the Mid-Atlantic Ridge are not sensed by or does not dominate shear-wave splitting.

In this study, we present new SKS and SKKS splitting data from the HOTSPOT and SIL networks. We use these measurements to constrain the flow of Icelandic upwelling material. The increased number of stations used provides the most detailed map of splitting observations across Iceland thus far. After constraining the depth of the anisotropy, and considering 
the effect of water plus stress and melt on the relationship between anisotropy and flow, we conclude that upwelling material flows from the upwelling axis northwestward towards the southern end of the Kolbeinsey Ridge. The splitting observations are inconsistent with radial flow of material away from the upwelling and we hypothesize that upwelling material instead feeds asthenospheric channels between the Kolbeinsey and Reykjanes Ridges.

\section{Data and method}

In our study, we used a total of 40 seismic stations from the HOTSPOT and SIL networks (Fig. 1). The HOTSPOT network was a temporary PASSCAL deployment of broadband instruments from July 1996 till July 1998 [3]. We also included 11 broadband stations from the Southern Iceland Lowlands project (SIL network) [32], which provided high quality data during the same period. Among 658 teleseismic events with magnitude equal to or greater than 5.5 and epicentral distances equal to or greater than $85^{\circ}$, 28 events provided useful data (Fig. 2, Table 1). For

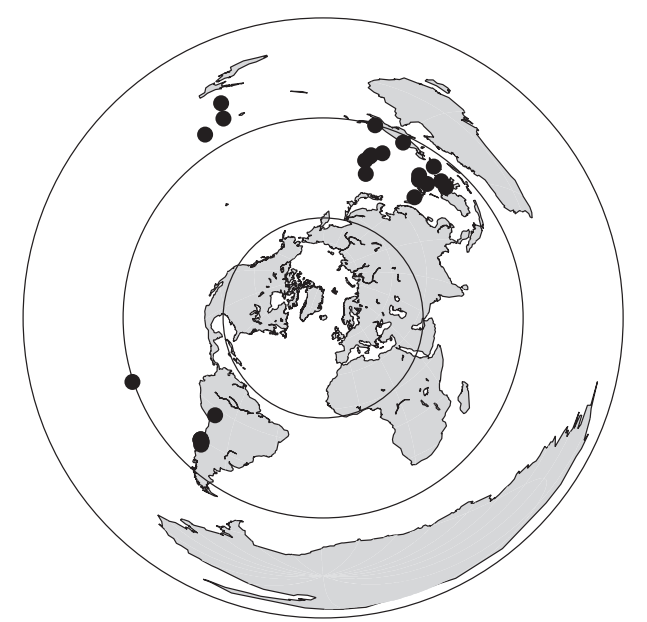

Fig. 2. Distribution of the 28 events used in this study. The black dots indicate the locations of earthquakes, and gray circles mark $60^{\circ}, 120^{\circ}$, and $180^{\circ}$ from Iceland.

data to be useful the SKS or SKKS core phases must be well separated from other phases such as $\mathrm{S}$ and $\mathrm{ScS}$ and have a high signal-to-noise ratio on the transverse seismogram. Generally, events with magnitude in the range of 6.3 to 6.8 and epicenter distance around $100^{\circ}$ provide a relatively large number of useful events.

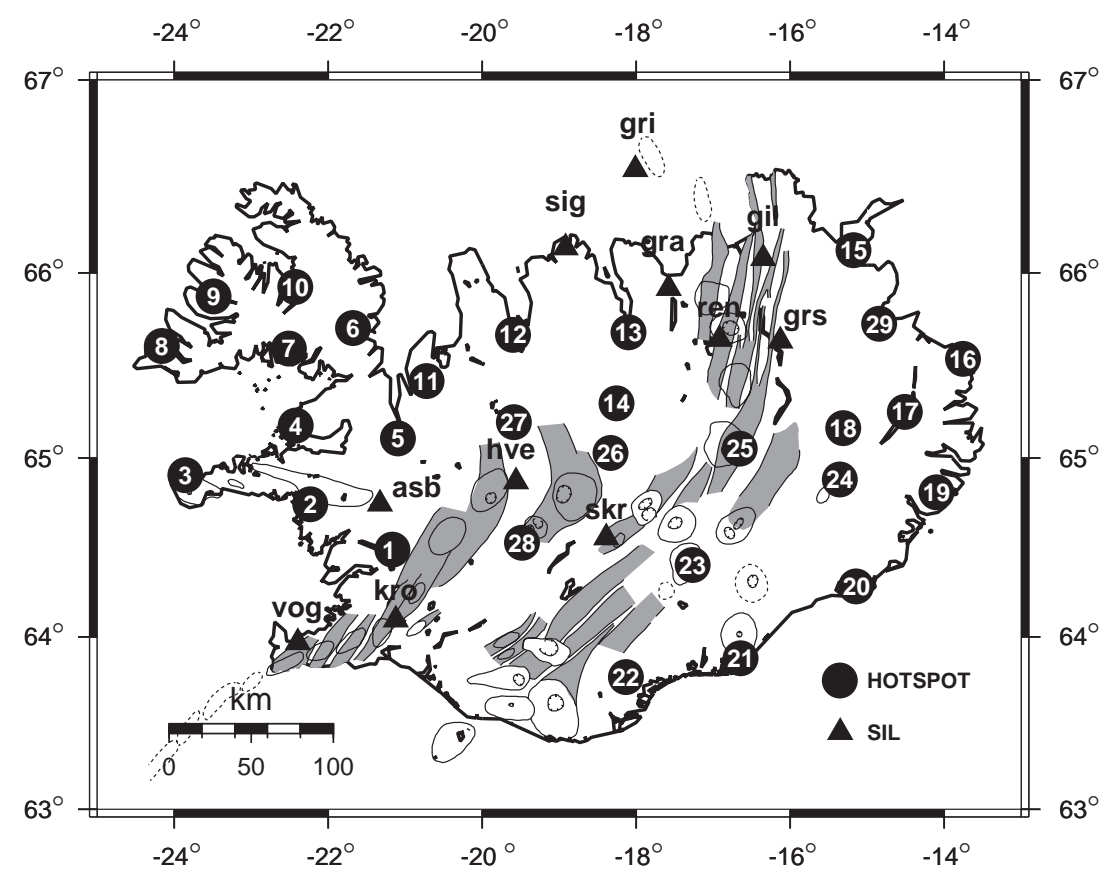

Fig. 1. Seismic stations used in this study: HOTSPOT (circles) and SIL (triangles) stations. The gray segments show fissure swarms indicating where the Mid-Atlantic Ridge crosses the island, and the circular features represent central volcanoes. 
Table 1

Earthquakes used in study

\begin{tabular}{|c|c|c|c|c|c|c|c|c|}
\hline No. & $\mathrm{Y} / \mathrm{M} / \mathrm{D}$ & $\begin{array}{l}\text { Julian } \\
\text { day }\end{array}$ & Time & Latitude & Longitude & Depth $(\mathrm{km})$ & Magnitude & $\begin{array}{l}\text { Epicenter } \\
\text { distance }\left({ }^{\circ}\right)\end{array}$ \\
\hline 1 & $1996 / 07 / 04$ & 186 & 155038.70 & 8.49 & 141.56 & 33. & 5.9 & 105.1 \\
\hline 2 & $1996 / 07 / 16$ & 198 & 100736.65 & 1.02 & 120.25 & 33. & 6.6 & 107.5 \\
\hline 3 & $1996 / 07 / 22$ & 204 & 141935.77 & 1.00 & 120.45 & 33. & 7.0 & 107.6 \\
\hline 4 & $1996 / 08 / 05$ & 218 & 223822.09 & -20.69 & -178.81 & 550. & 7.4 & 133.8 \\
\hline 5 & $1996 / 09 / 20$ & 264 & 000318.37 & 9.60 & 126.29 & 33. & 6.4 & 101.0 \\
\hline 6 & $1996 / 09 / 20$ & 264 & 041027.68 & 9.46 & 126.28 & 33. & 6.6 & 101.1 \\
\hline 7 & $1996 / 09 / 20$ & 264 & 041104.55 & 9.45 & 126.33 & 33. & 6.6 & 101.1 \\
\hline 8 & $1997 / 03 / 11$ & 70 & 192200.13 & 7.74 & 127.65 & 10. & 7.2 & 103.1 \\
\hline 9 & $1997 / 05 / 09$ & 129 & 090637.27 & 13.20 & 144.70 & 29. & 6.1 & 100.9 \\
\hline 10 & $1997 / 05 / 22$ & 142 & 132136.35 & 18.92 & 121.34 & 33. & 6.1 & 90.8 \\
\hline 11 & $1997 / 05 / 27$ & 147 & 150903.76 & 16.33 & 145.44 & 536. & 5.6 & 97.9 \\
\hline 12 & $1997 / 06 / 24$ & 175 & 230453.14 & -1.92 & 127.90 & 33. & 6.4 & 112.5 \\
\hline 13 & $1997 / 07 / 06$ & 187 & 095400.76 & -30.06 & -71.87 & 19. & 6.8 & 103.5 \\
\hline 14 & $1997 / 07 / 06$ & 187 & 231520.49 & -30.16 & -71.86 & 33. & 5.8 & 103.6 \\
\hline 15 & $1997 / 07 / 08$ & 189 & 022407.32 & 23.80 & 142.70 & 33. & 5.8 & 90.2 \\
\hline 16 & $1997 / 07 / 21$ & 202 & 231939.35 & -30.33 & -71.92 & 33. & 6.0 & 103.8 \\
\hline 17 & $1997 / 07 / 27$ & 208 & 052129.27 & -30.52 & -71.86 & 33. & 6.3 & 104. \\
\hline 18 & $1997 / 10 / 04$ & 277 & 183141.05 & -35.29 & -106.71 & 10. & 5.7 & 120.9 \\
\hline 19 & $1997 / 10 / 08$ & 281 & 104749.92 & -29.25 & 178.35 & 617. & 5.7 & 142.8 \\
\hline 20 & $1997 / 10 / 15$ & 288 & 010333.46 & -30.93 & -71.22 & 58. & 7.6 & 104.1 \\
\hline 21 & $1997 / 11 / 25$ & 329 & 121433.63 & 1.24 & 122.54 & 24. & 7.0 & 108.0 \\
\hline 22 & $1997 / 11 / 28$ & 332 & 225341.53 & -13.74 & -68.79 & 586. & 6.7 & 87.3 \\
\hline 23 & $1997 / 12 / 22$ & 356 & 020550.08 & -5.49 & 147.87 & 179. & 7.2 & 119.8 \\
\hline 24 & $1998 / 05 / 23$ & 143 & 174447.77 & 8.14 & 123.73 & 657. & 6.0 & 101.7 \\
\hline 25 & $1998 / 06 / 09$ & 160 & 120455.32 & -18.87 & -173.31 & 33. & 5.5 & 131.0 \\
\hline 26 & $1998 / 06 / 22$ & 173 & 202624.91 & 12.36 & 144.45 & 33. & 5.7 & 101.7 \\
\hline 27 & $1998 / 07 / 29$ & 210 & 071424.08 & -32.31 & -71.29 & 51. & 6.3 & 105.5 \\
\hline 28 & $1998 / 07 / 29$ & 210 & 180029.99 & -2.69 & 138.90 & 33. & 6.7 & 115.6 \\
\hline
\end{tabular}

The back azimuths of the 28 useful events fall into three groups: $9-45^{\circ}, 220-255^{\circ}$, and $327-347^{\circ}$, as shown in Fig. 2. In total, 258 shear-wave splitting measurements were made in this study.

We followed the method of Silver and Chan $[33,34]$ to calculate the shear-wave splitting parameters $\phi$ (the splitting direction) and $\delta t$ (the delay time) for individual earthquakes and then followed a multi-event stacking procedure of Wolfe and Silver [35] to stack the error surfaces of individual earthquakes and reduce the uncertainty in estimated $\phi$ and $\delta t$ at each station. We low-pass filtered all teleseismic phases at $10 \mathrm{~s}$ to reduce microseismic noise before making splitting measurements.

We observed many null results (by which we mean zero or little energy on the transverse component) in western Iceland. A null observation suggests there is either isotropic structure beneath the station or there is anisotropy but the fast axis is near-parallel or -perpen- dicular to the initial polarization direction (the radial direction for SKS). Calculation of the energy on the corrected transverse component for the usual range of $\phi$ and $\delta t$ results in a broad minimum and elongated double contours in $\delta t$ direction within $10-15^{\circ}$ of a direction parallel or perpendicular to the back azimuth [36]. Correspondingly, including null splits in stacking can constrain fast splitting directions while leaving the splitting delays unconstrained. We can therefore include null observations in our stacking procedure using multiple events recorded.

\section{Splitting results}

The splitting parameters for the HOTSPOT and SIL networks derived by the stacking procedure of Wolfe and Silver [35] are given in Table 2. The splitting results fall into two groups as shown in 
Table 2

Shear-wave splitting parameters for HOTSPOT and SIL stations

\begin{tabular}{|c|c|c|c|c|c|}
\hline Station & $\phi\left(^{\circ}\right)$ & $\sigma_{\phi}\left({ }^{\circ}\right)$ & $\delta t(\mathrm{~s})$ & $\sigma_{\delta t}(\mathrm{~s})$ & $n$ \\
\hline HOT01 & 36 & 11 & 0.65 & 0.30 & 11 \\
\hline НОТ02 & 20 & 5 & 1.20 & 0.35 & 9 \\
\hline НОТ03 & \multicolumn{4}{|c|}{ All null results } & 2 \\
\hline НОТ04 & -30 & 21 & 0.50 & 0.20 & 13 \\
\hline HOT05 & 7 & 21 & 0.40 & 0.175 & 7 \\
\hline HOT06 & -22 & 22.5 & 0.20 & 0.3 & 15 \\
\hline НОТ07 & 25 & 1 & 2.80 & 0.35 & 11 \\
\hline НОТ08 & 13 & 22.5 & 0.35 & 0.35 & 13 \\
\hline НОТ09 & -3 & 22.5 & 0.10 & 0.2 & 11 \\
\hline HOT10 & 2 & 7.5 & 0.80 & 0.125 & 12 \\
\hline HOT11 & \multicolumn{4}{|c|}{ All null results } & 6 \\
\hline HOT12 & -43 & 2 & 2.00 & 0.45 & 7 \\
\hline HOT13 & -32 & 5.5 & 1.25 & 0.225 & 8 \\
\hline HOT14 & -39 & 4 & 1.00 & 0.2 & 12 \\
\hline HOT15 & -22 & 6.5 & 1.25 & 0.2 & 5 \\
\hline HOT16 & -19 & 2 & 1.20 & 0.15 & 11 \\
\hline HOT17 & -22 & 2.5 & 1.20 & 0.125 & 13 \\
\hline HOT18 & -27 & 3 & 1.45 & 0.175 & 6 \\
\hline HOT19 & -22 & 5.5 & 1.35 & 0.20 & 3 \\
\hline НОТ20 & -3 & 5 & 0.85 & 0.05 & 7 \\
\hline НОT21 & \multicolumn{4}{|c|}{ All null results } & 5 \\
\hline HOT22 & \multicolumn{4}{|c|}{ All null results } & 5 \\
\hline НОТ23 & -17 & 11 & 0.80 & 0.225 & 6 \\
\hline НОТ24 & -11 & 4 & 1.25 & 0.1 & 5 \\
\hline НОТ25 & -22 & 12.5 & 0.90 & 0.25 & 5 \\
\hline НОT26 & \multicolumn{4}{|c|}{ All null results } & 2 \\
\hline НОТ27 & -47 & 1.5 & 1.70 & 0.225 & 8 \\
\hline HOT28 & -44 & 2.5 & 1.75 & 0.325 & 6 \\
\hline НОТ29 & -17 & 4.5 & 1.45 & 0.425 & 3 \\
\hline ASB & 24 & 22.5 & 0.90 & 0.65 & 4 \\
\hline VOG & \multicolumn{4}{|c|}{ All null results } & 1 \\
\hline GRI & -33 & 9.5 & 1.40 & 0.425 & 4 \\
\hline HVE & \multicolumn{4}{|c|}{ All null results } & 3 \\
\hline KRO & -63 & 3.5 & 1.40 & 0.25 & 3 \\
\hline SIG & -43 & 2 & 2.30 & 0.525 & 5 \\
\hline SKR & \multicolumn{4}{|c|}{ All null results } & 1 \\
\hline GIL & -36 & 22.5 & 1.50 & 1.175 & 2 \\
\hline GRA & 1 & 9.5 & 1.10 & 0.25 & 4 \\
\hline GRS & -7 & 6.5 & 1.45 & 0.175 & 2 \\
\hline REN & \multicolumn{4}{|c|}{ All null results } & 2 \\
\hline
\end{tabular}

The $\sigma_{\phi}$ and $\sigma_{\delta t}$ are the standard deviations in $\phi$ and $\delta t$, respectively, and $n$ is the stacked number of records for each station.

Fig. 3: (1) in western Iceland the average fast splitting direction is $\mathrm{N} 21^{\circ} \mathrm{E}$ with an average delay time $0.6 \mathrm{~s}$; (2) in central and eastern Iceland: the average fast splitting direction is $\mathrm{N} 27^{\circ} \mathrm{W}$ with an average delay time $1.4 \mathrm{~s}$. Two subgroups are also observed in central and eastern Iceland with the Mid-Atlantic Ridge as the dividing line: the average fast splitting direction is $\mathrm{N} 38{ }^{\circ} \mathrm{W}$ with an average delay time $1.5 \mathrm{~s}$ in central
Iceland and the average fast splitting direction is $\mathrm{N} 17^{\circ} \mathrm{W}$ with an average delay time $1.2 \mathrm{~s}$ in eastern Iceland. Generally, the splitting results for central and eastern Iceland are very well constrained, whereas the splitting results for western Iceland show weak to negligible anisotropy with less well-constrained splitting directions.

Comparison of our splitting observations with regional anisotropic models shows broad consistency. Pilidou et al. [37] use Rayleigh waves to constrain anisotropy in the upper few hundred kilometers of the North Atlantic and western Europe. They observe a rotation of the fast axis orientation from $\mathrm{N}-\mathrm{S}$ west of Iceland to NW-SE east of Iceland (the lateral resolution is several hundred kilometers), which is consistent with the trend we see from west to east across Iceland. Compared with the two previous studies of shear-wave splitting across Iceland [30,31], we add new observations at HOT27, HOT12, HOT11, HOT14, HOT26, and all SIL stations. Although most of our splitting observations are consistent with previous studies, there are two exceptions at station HOT27 and HOT12 in central Iceland (Fig. 3). At station HOT27, the splitting direction we observed is NW-SE, which is almost perpendicular to NE-SW observed by Li and Detrick [31] and NNE-SSW observed at nearby station BLOL by Bjarnason et al. [30]. At station HOT12, the splitting direction we observed is NW-SE, different from N-S observed by $\mathrm{Li}$ and Detrick [31]. We note that the NW-SE fast axes indicated by our splitting observations at HOT12 and HOT27 are consistent with observations at surrounding stations. Fig. 4 shows the splitting parameters of $\phi$ as a function of event back-azimuth at station HOT27 and HOT12. On the basis of consistency between adjacent stations we also expect a NW-SE fast axis for HOT11. However we can only make null observations given the limited range of back azimuths to events providing good SKS observations at HOT11. These nulls could indicate isotropic structure or anisotropy with a fast axis parallel or perpendicular to the back azimuth. In the case of HOT11, we prefer an interpretation with a NW-SE oriented fast axis, i.e. anisotropy similar to surrounding stations. We also performed bootstrap tests of stacked splitting parameters to new observations at HOT27, HOT12, HOT13, HOT14, SIG, and GRI, showing that these new observations are robust. 


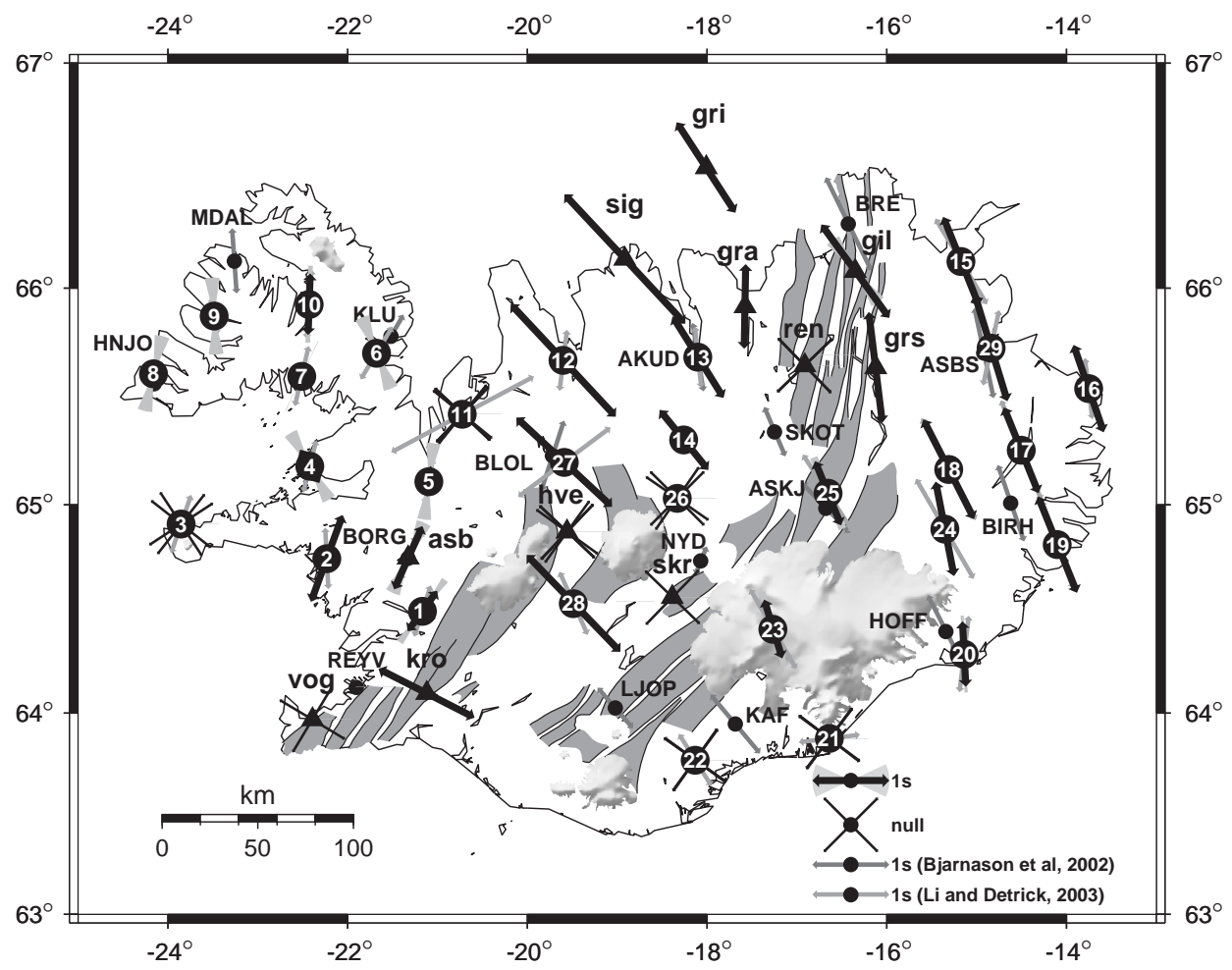

Fig. 3. Splitting results across Iceland. At each station the line orientation gives the fast splitting direction $\phi$, and its length is linearly proportional to $\delta t$. The black lines indicate the results from our study with the thickest lines indicating fast axis orientation and thin crosses indicating null results. The light gray wedges indicate the $95 \%$ confidence region in the polarization direction. The thin dark gray lines indicate the results from Bjarnason et al. [2002]; the thin light gray lines indicate the results from Li and Detrick [2003]. Also indicated are the neovolcanic zones (gray region) and glaciers (light gray shades).

(a)

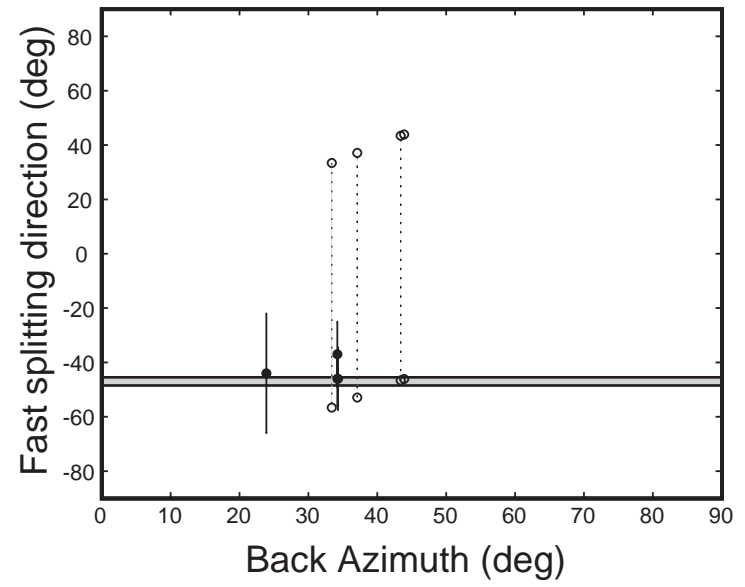

(b)

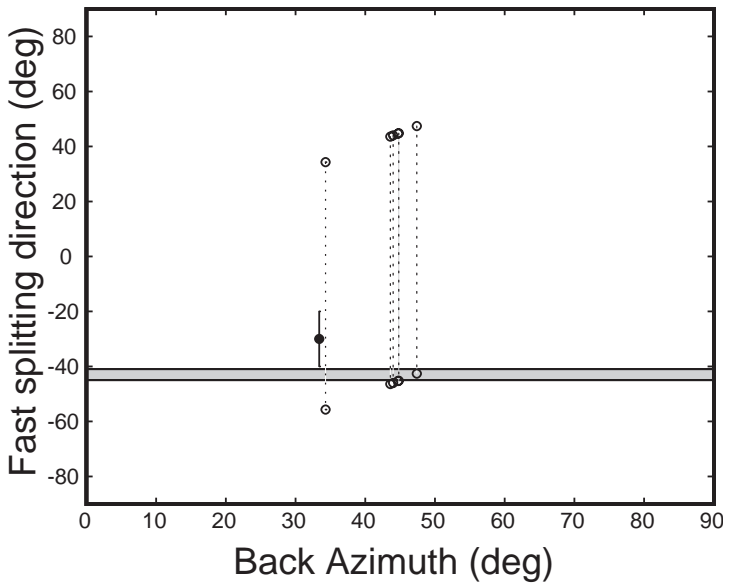

Fig. 4. Fast splitting directions $\phi$ as a function of event back-azimuth for station HOT27 (a) and HOT12 (b). Black dots and vertical solid lines indicate $\phi$ and corresponding uncertainties, respectively. Circles connected by dotted lines indicate the two candidate fast directions from null results. Horizontal gray bars illustrate the best fit $\phi$ calculated from stacking the splitting observation from all the events. 
In our study, after stacking 11 events at station HOT07, we observed a very large apparent splitting time of $2.8 \mathrm{~s}$. For each event, we observed only negligible energy with respect to noise levels on the original transverse seismogram, energy contours elongating in the $\delta t$ direction, and/or poorly constrained optimal $\phi$ and $\delta t$. The apparently large $\delta t$ is therefore more likely due to noise rather than real signal and was discarded.

\section{Interpretation of shear-wave splits}

\subsection{Source depth of the anisotropic signal}

Because the conversion from an S- to P-wave in the outer core removes any splitting due to the source-side of the path, SKS splitting measurements represent an integral along the mantle ray path on the receiver side. As the ray path is nearly vertical through the mantle and crust, the anisotropy is located within a nearly vertical column beneath the station. Silver [38] studied contributions of various layers in the Earth to SKS splitting times. He found the average contribution from the crust to be $0.2 \mathrm{~s}$, and the contribution from the lower mantle and transition zone to be typically less than $0.2 \mathrm{~s}$. He concluded that the SKS splitting times (with typical values of $1 \mathrm{~s}$ ) arise primarily from anisotropy in the upper mantle beneath the Moho [38]. In Iceland, splitting times of $0.1-0.3 \mathrm{~s}$ are observed in the crust beneath the Western Volcanic Zone and smaller splitting times of $0.1 \mathrm{~s}$ are observed in South Iceland Seismic Zone [39]. Our observed SKS splitting times of up to $2 \mathrm{~s}$ therefore suggest that any crustal contribution to SKS splitting times is small and the upper mantle is the primary source.

Two features of our data also suggest that the anisotropy we observed is in the upper mantle. Firstly, the close proximity of adjacent stations in Iceland results in near-identical lower-mantle ray paths from a single event. It is only in the upper mantle that ray paths to western and central Iceland are distinct while differences in splitting time of up to $1 \mathrm{~s}$ are observed. This requires strongly heterogeneous anisotropy in the upper mantle. Secondly, the insensitivity of the fast axis orientation at a single station to event back azimuth implies a shallow source as it is only in the upper few hundred kilometers that rays from multiple events to the same station share the same path.

We conclude that in central and eastern Iceland the upper mantle is the primary source of anisotropy for the following reasons: (1) the previously observed crustal splitting times are roughly a factor of six smaller than what we observed in central and eastern Iceland, (2) our splitting times do not correlate with crustal thickness, and (3) splitting orientations do not correlate with surface structures. In western Iceland, the contribution of the crust may be more important. Our splitting observations in the Westernfjords are only a factor of 2 to 3 greater than typical crustal splitting times. This may suggest that the upper mantle is more isotropic or the apparent thickness of the asthenospheric layer of anisotropy is thinner beneath western Iceland.

\subsection{Single layer of anisotropy}

Our interpretation of the SKS splitting observations assumes a single layer of uniform anisotropy. If there were multiple layers of anisotropy, there would be a dependence of splitting times and/or spitting directions on back azimuth. In our splitting observations, neither $\phi$ nor $\delta t$ show a significant dependence on back azimuth. Fig. 5a and b show the splitting parameters of $\phi$ and $\delta t$ as a function of event backazimuth at station HOT17. Splitting observations for individual events are quite uniform with small variations for different back-azimuths, indicating that a single layer of anisotropy dominates the observations. Further, we observe null splits at more than ten stations for events whose back azimuth is near-parallel or -perpendicular to the splitting directions observed using other events. If there was more than one layer of anisotropy, a null result could not be observed except in the unusual case in which different layers cancel the anisotropy of one another exactly. Given the incomplete coverage of event back azimuth and the low frequency of the SKS waveforms used, it is still possible that additional layers of relatively thin anisotropy are present beneath Iceland. If such layers exist, they are most likely beneath western Iceland as the area shows weak anisotropy with less well-constrained splitting directions. Similar splitting observations have been made in the case of layered structures 
(a)

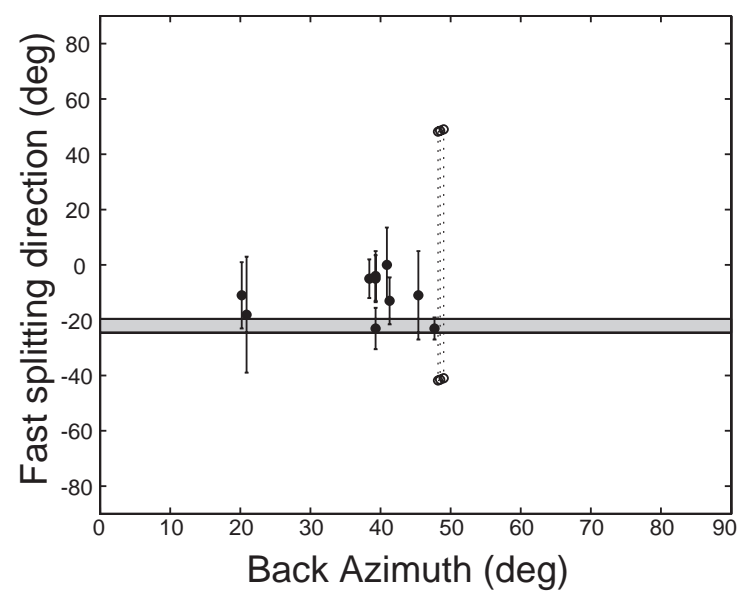

(b)

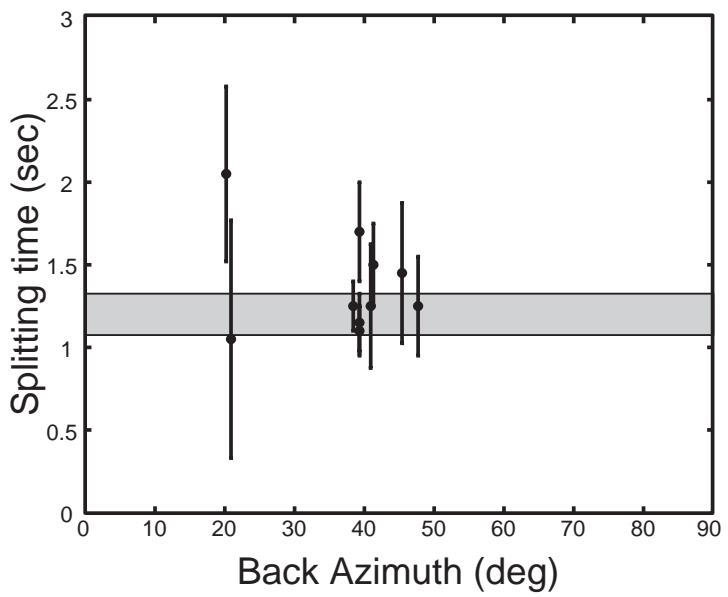

Fig. 5. Splitting parameters (a) $\phi$ and (b) $\delta t$ as a function of event back-azimuth for station HOT17. Black dots indicate $\phi$ in (a) and $\delta t$ in (b). Other symbols have the same meaning as in Fig. 4.

[40] or vertical heterogeneity [41]. In central and eastern Iceland we interpret our splitting results in terms of a single layer of anisotropy by which we mean a single layer of anisotropy dominates the splitting observations.

It is impossible to determine the thickness of an anisotropic layer generating SKS splits as the layer thickness and strength of the anisotropy trade off against one another. To get a sense of the order of magnitude of the thickness of the anisotropic layer beneath Iceland we assume that the strength of anisotropy is similar to the average $4 \%$ anisotropy observed in natural peridotites from 120 to $170 \mathrm{~km}$ depth [42]. Given $4 \%$ anisotropy a $2 \mathrm{~s}$ delay would be generated by a $200 \mathrm{~km}$ thick layer.

\subsection{Relating flow to the fast splitting direction}

The relation between the mantle flow direction and mineral preferred orientation is complicated as different olivine fabrics develop not only for different types of deformation, such as simple shear, pure shear, and axial compression, but also with different strain amplitudes (e.g., [43-47]). While simple shear is believed to be the dominant mode of deformation in the upper mantle (e.g., $[45,48])$, deformation types other than simple shear may exist in the vicinity of Icelandic upwelling. When flow occurs in simple shear the olivine a axis tracks with the strain ellipsoid. For relatively small strains (e.g., lower than $\sim 75 \%$ [48]), olivine a axes are closely aligned with the principal axis of strain ellipsoid within the foliation plane, and at an angle of $45^{\circ}$ counterclockwise from the flow direction $[43,47,48]$. With progressive strain, olivine a axes follow the strain ellipsoid and rotate towards the flow plane $[43,47]$ becoming subparallel to the flow direction for large strains $(\sim 150 \%)$ [48]. Thus olivine a axes are expected to be parallel to asthenospheric flow for large strain by simple shear. Given the complex flow close to the upwelling conduit beneath Iceland (within $\sim 100 \mathrm{~km}$ ) we cannot assume simple shear across a horizontal plane. Instead we might expect more variable crystallographic orientations due to both different types of deformation and magnitudes and orientations of strain. An SKS phase traveling through such complex structure would not develop a simple split due to reduced amplitude on the tangential component caused by scattering [41]. We would therefore expect null or small delay time splitting observations close the upwelling axis. In our interpretation we make the simplifying assumption that away from the upwelling conduit material is flowing away from Iceland by simple shear on a horizontal plane. Close to the upwelling axis the more complex relationship between crystallographic axes and flow is likely to result in small or no splitting delays. Given the assumption of simple shear, we must still consider the effect of water [49] and melt 
[50] on the relationship between flow direction and crystallographic orientation, both of which are possible beneath Iceland.

\subsubsection{The influence of water on the fast splitting direction}

The experimental study by Jung and Karato [49] questions the assumption that flow directions are generally parallel to the seismically fast splitting direction corresponding to the type-A fabric of olivine. Their results show that when water is added to olivine, the relation between seismic anisotropy and flow geometry undergoes marked changes. In addition to the wellknown type-A fabric in which the olivine [100] axis is subparallel to the shear direction and the (010) plane is subparallel to the shear plane, they identified two new types of fabric: type-B and type-C. In type-B, the olivine [001] axis is subparallel to the shear direction and the $(010)$ plane is subparallel to the shear plane. In type- $C$, the [001] axis is subparallel to the shear direction and the (100) plane is subparallel to the shear plane. In addition to the above three types of fabric, a fourth type of fabric, type- $\mathrm{D}$, has been reported [51]. Type-D develops at high strain, and has a sharp [100] maximum oriented parallel to the shear direction and girdles of [010] and [001] normal to that direction. Jung and Karato [49] concluded that type-A dominates at low stress and low water content, type-B dominates at high water content and/or high stress, type-C dominates at high water content and modest stress, and type-D dominates at high stress and low water content. In type-A, type-C, and type-D fabrics, the fast splitting direction of an S-wave is subparallel to the flow direction (in a horizontal flow for type-A and type-C; the shear plane can not be identified for type-D); whereas in type-B fabric, the fast splitting direction of the $\mathrm{S}$-wave is nearly perpendicular to the flow direction (in a horizontal flow) [49,51]. Although type-B fabric has a significant influence on the lattice preferred orientation, the required conditions for type-B fabric to dominate (high stress and high water content) are not common in the mantle [52]. Thus before interpreting our splitting observations, it is important to know the water content and the state of stress beneath Iceland to derive the fabrics of olivine and corresponding relations between the fast splitting direction and the flow direction.
Geochemical studies suggest that Iceland is not only a hotspot but also a wetspot. A comprehensive petrological and geochemical study of basalts dredged along the axis of the Mid-Atlantic Ridge from $29^{\circ} \mathrm{N}$ to $73^{\circ} \mathrm{N}$ shows that the mantle beneath Iceland is enriched in water [53]. Water concentrations show an increasing trend from south of $61^{\circ} \mathrm{N}$ to Iceland [14], reaching $0.47 \mathrm{wt} . \%$ in Iceland [54]. They are 1.5 to 4 times higher than typical mid-ocean ridge basalts (0.12 wt.\%; [55]). Water concentrations of between 620 and 920 ppm have also been measured in basaltic glasses from submarine and subglacial eruption sites along the Reykjanes Ridge and Iceland, respectively [56]. All these observations suggest that Iceland is a wet hotspot.

Stress is the other key factor to decide the dominant fabric type of olivine beneath Iceland. Although there are no direct stress measurements available for the Icelandic upper mantle, we assume that the state of stress beneath Iceland is similar to that beneath typical rift zones as Iceland is located on the Mid-Atlantic Ridge. Peridotites from typical rift-zone environments and xenoliths from ocean island basalts show stress magnitudes of $\sim 1$ to $10 \mathrm{MPa}$ [57]. Therefore, we expect the magnitude of stress to be low. In such low stress and medium to high water content (between 620 and 920 $\mathrm{ppm})$ environments, type-A and type-C fabrics of olivine dominate [49]. Both type-A and type-C fabric of olivine result in the fast splitting direction of a shear-wave with a nearly vertical ray path being parallel to the flow direction (in a horizontal flow). Thus, despite the high water content, the parallelism between the seismic fast axis and the flow direction should hold beneath Iceland due to the expected low stress environment.

\subsubsection{The influence of melt on the fast splitting direction}

Holtzman et al. [50] deformed partially molten mantle rocks under anhydrous conditions and observed that melt-rich layers cause a switch of the $a$ - and $c$-axes, resulting in a fast direction perpendicular to the shear direction. The importance of this observation for the interpretation of anisotropy beneath Iceland is dependent on the percentage of melt in the mantle beneath Iceland and its geometric extent, which we now consider. 
Geophysical studies of the uppermost mantle beneath Iceland do not require the presence of melt to explain velocity anomalies which has lead to an estimated upper bound of $1 \%$ melt fraction $[7,58]$. More recently, observed disequilibrium of U-series activity ratios in Iceland requires melt to separate from the source region when the melt fraction exceeds a few tenths of a percent, and suggests that the melt reaches the surface within 20 years [59]. These observations indicate that only a small melt fraction is retained beneath Iceland. In comparison, the experiments of Holtzman et al. [50] used samples with melt fractions ranging from $2 \%$ to $15 \%$, although more recent experiments with as little as $0.5 \%$ melt also show the melt bands resulting in a switch of the $a$ - and $c$-axes (Holtzman, personal communication). It is therefore likely that the melt fraction beneath Iceland is less than in the experiments of Holtzman. However, it is still possible that a similar switch of the $a$ - and $c$ axes occurs for the very low percentage of melt we expect beneath the region.

Inversion results using REE compositions of the olivine tholeiites from Iceland suggest that melting initiates at a depth of 120 to $140 \mathrm{~km}$, and stops at depths as shallow as 20 to $22 \mathrm{~km}$ [60-63]. Both geochemical [63] and volumetric arguments [1] suggest there is buoyant upwelling beneath Iceland as mantle material is fluxed through the melt zone more rapidly than passive upwelling would allow. Numerical models [64] show that in buoyant upwelling, melt is focused within a narrow zone about $50 \mathrm{~km}$ across beneath a ridge compared to the much broader $\sim 150$ $\mathrm{km}$ wide zone of melting when upwelling is passive. If there is any effect of melt on splitting observations beneath Iceland it is therefore most likely confined to a narrow region a few tens of kilometers wide beneath the ridge. Pilidou et al. [37] completed a regional Rayleigh wave study of anisotropic velocity structure beneath the North Atlantic. Their study is not sensitive to variations in anisotropy on a scale less than $\sim 400$ $\mathrm{km}$ and shows a rotation of the fast axes from NNWSSE east of Iceland to more N-S west of Iceland in the upper $250 \mathrm{~km}$. Given the sensitivity of Pilidou et al.'s Rayleigh wave study their observations are not sensitive to melt beneath the Icelandic mid-ocean ridge. Our splitting observations show the same trend as Pilidou et al. with fast axis orientations NNW-SSE in eastern and central Iceland, and N-S in western Iceland implying that our observations are not sensitive to any melt either.

In our following interpretation we neglect any effect of melt on the orientation of crystallographic axes with respect to flow. We make this assumption on the basis that (1) the percentage of melt beneath Iceland is smaller than in the Holtzman experiments, (2) any melt is probably focused in a narrow region beneath the ridge, and (3) our observations are consistent with the broad trend of Pilidou et al. [37] which is not sensitive to melt.

\subsection{Comparison of splits with conceptual mantle flow geometries}

Bjarnason et al. ([30] and references therein) summarized five potential conceptual horizontal mantle flow geometries beneath Iceland: flow associated with relative plate motion perpendicular to the ridge, flow associated with absolute plate motion, background mantle flow, hotspot-related radial flow, and rift-parallel flow. We now compare the orientations of our splitting observations with the anticipated flow geometries from these models.

In the flow geometry associated with relative plate motion, mantle material rises beneath the ridge axis and spreads in the direction of relative plate motion, perpendicular to the ridge. For this geometry, we would expect weak splitting in the neovolcanic zone due to the nearly vertical $a$-axes of olivine associated with upwelling, and strong splitting with the fast splitting direction aligned with the spreading direction WNW-ESE away from the ridge. This ridge perpendicular geometry has been observed previously at fast-spreading mid-ocean ridges such as the East Pacific Rise $[65,66]$. Our splitting observations are not ridge perpendicular, suggesting that this flow geometry has little contribution to mantle anisotropy beneath Iceland.

If the flow associated with absolute plate motion is the cause of the anisotropic structure beneath Iceland, we would expect splitting observations east of the ridge to represent the Eurasian plate motion while splits to the west represent the North American plate motion. Absolute plate motion in western Iceland is in a westerly direction while in eastern Iceland, the plate velocity is not significantly different from zero [67]. Thus we would expect strong splitting with a westerly 
fast splitting direction in western Iceland and negligible splitting in eastern Iceland. This also does not match our splitting observations.

If background mantle flow is responsible for the anisotropic structure, we would expect uniform splitting with a coherent fast splitting direction throughout Iceland, because the background mantle flow is expected to be homogeneous across Iceland, although its direction is unknown. Instead, our splitting observations show a range of fast axis orientations.

In the hotspot-related radial flow geometry (Fig. $6 a)$, material rises vertically at the center of the upwelling conduit and diverges radially from the upwelling axis at the base of the lithosphere. We would therefore expect weak splitting at the center of the upwelling due to vertically aligned olivine $a$-axes surrounded by a radial pattern of fast splitting directions. The amplitude of our observed splits is noticeably smaller in the region of upwelling centered close to HOT23, Fig. 3, and in north-central Iceland our fast splitting directions do show a gradual rotation consistent with a radial pattern away from the upwelling center. However, in western and eastern Iceland, our fast splitting directions are almost perpendicular to the predicted radial pattern.

In the rift-parallel flow geometry (Fig. 6b), mantle material flows along the rift zones and we expect fast splitting directions parallel to the rifts. Most of the North American-Eurasian spreading is accommo- dated by the northern and eastern neovolcanic zones as indicated by the plate boundary on Fig. 6b. Thus the Mid-Atlantic plate boundary in Iceland is offset $200 \mathrm{~km}$ to the east with respect to the plate boundary to the north and south of Iceland. It is therefore possible that any rift-parallel flow is occurring at two scales. At the smaller scale, just beneath Iceland, rift-parallel flow would be $\mathrm{N}-\mathrm{S}$ beneath the neovolcanic zones. At the larger scale of the North Atlantic, rift-parallel flow would be NE-SW and run beneath western Iceland. This anticipated rift-parallel flow geometry fits our splitting observations in western and eastern Iceland, but does not match observations in central Iceland.

Bjarnason et al. [30] interpreted their splitting observations on Iceland as the result of relative plate motion over background mantle flow. This model predicts that splitting observations align with the vector sum of the mantle flow and the plate motion resulting in one fast axis orientation for each plate. Their splitting observations fell into two groups with one consistent fast direction for the North American plate and one for the Eurasian plate. This is not the case for our observations as the fast directions in western Iceland are very different from those in central Iceland while all being on the North American plate. The variation in fast direction on the North American plate was not as apparent in Bjarnason et al.'s study as they had fewer stations in westernmost Iceland. (a)

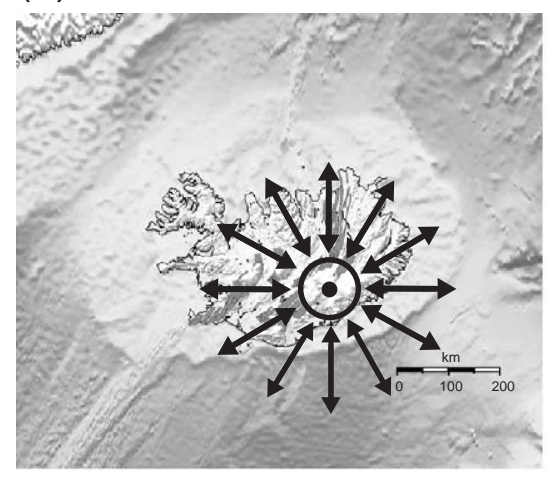

(b)

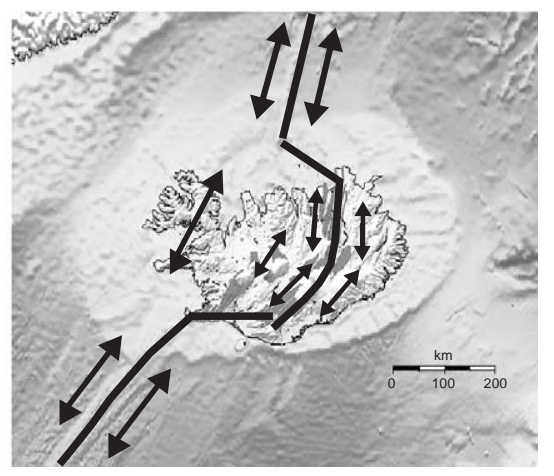

Fig. 6. Conceptual mantle flow geometries beneath Iceland. (a) The hotspot-related radial flow geometry. (b) The rift-parallel flow geometry. Black arrows show the expected horizontal mantle flow directions. The black circle and dot indicates the approximate location of the Icelandic hotspot, black line segments indicate the plate boundary between Eurasia and North America. 


\section{Ridge-channeled flow}

Although none of the individual models described above is completely consistent with our splitting observations, rift-parallel components are observed in western and eastern Iceland, and a radial geometry away from the axis of upwelling is observed in central Iceland. We therefore propose a hybrid ridge-channeled flow model which is consistent with most of our splitting observations and previous hypotheses for the flow path of mantle material upwelling beneath Iceland $[19,21-23,26]$. We propose that upwelling material is channeled along the North Atlantic Ridge rather than flowing radially away from the upwelling. For material to flow north and south away from Iceland along the Mid-Atlantic Ridge, upwelling material must flow from the upwelling center in SE Iceland to the southern end of the Kolbeinsey Ridge and the northern end of the Reykjanes Ridge both of which are west of the upwelling center (Fig. 7).

In central Iceland we suggest that the NW-SE orientation of fast axes indicate the flow of material from the upwelling toward the asthenospheric channel beneath the Kolbeinsey Ridge. The rotation of fast axes to more NNW-SSE direction in northeastern Iceland is consistent with both radial flow away

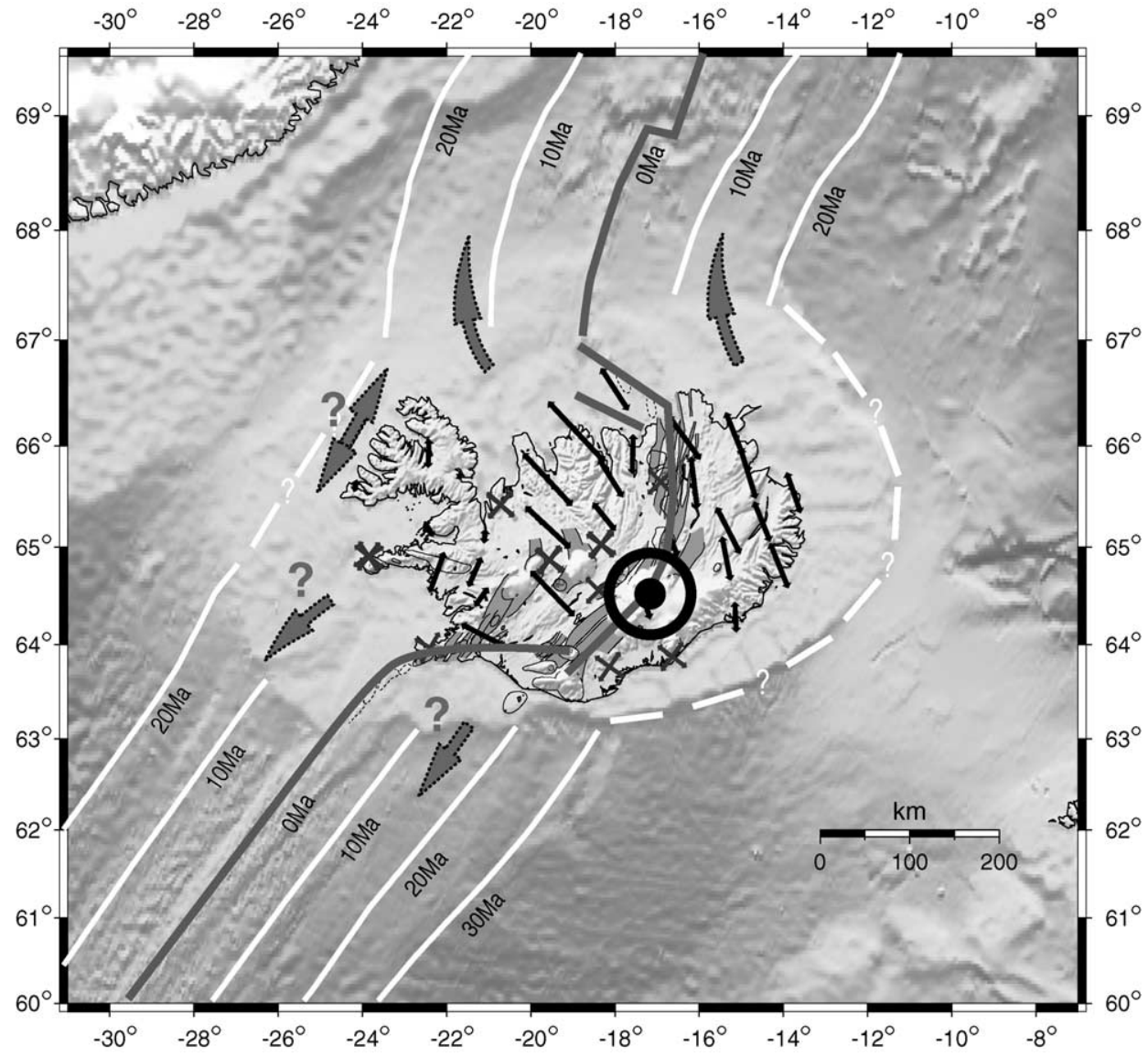

Fig. 7. Map placing asthenospheric anisotropy observations in the context of the proposed ridge-channeled flow model. The black circle with a dot indicates the center of the Icelandic upwelling. The bold gray lines across central Iceland indicate the plate boundary in the North Atlantic including the eastward step of the ridge across Iceland. The white lines indicate the ages of the lithosphere on either side of the spreading ridge. The orientation and length of each short black line indicates the splitting direction and the splitting time, respectively. The thick gray arrows with dotted outlines show the proposed mantle flow directions resulting from preferentially channeling the horizontally spreading upwelled material to, and then along, the Mid-Atlantic Ridges to the south and north of Iceland. 
from the upwelling and flow toward our proposed asthenospheric channel to the north. The splitting observations in easternmost Iceland are inconsistent with a simple radial flow geometry, but are consistent with flow toward an asthenospheric channel beneath the Kolbeinsey ridge. In western Iceland, farther away from the Icelandic upwelling, the NNE-SSW orientation of fast axes is parallel to the trend of the Kolbeinsey and Reykjanes ridges.

It is also noticeable that the splitting delay times at stations surrounding the axis of upwelling (centered close to HOT23-see Figs. 3 and 7) are relatively small. A gradual increase in delay time with distance from HOT23 to the northeast is evident at stations HOT20, НОT25, НОT24, HOT18, etc. Station HOT22 and HOT21 to the south show only null observations, and stations in the southern half of central Iceland exhibit small delays or nulls with the exception of HOT28. This may reflect either vertical flow and vertical $a$-axes within the upwelling and/or a more complex flow geometry and variable crystallographic orientations resulting in scattering of polarized energy and reduced delay times as described in Section 4.3.

Southernmost Iceland does not provide splitting observations to support our hypothesis. Unfortunately there are few stations between the upwelling and the Reykjanes ridge with which to map flow. HOT21 and HOT22 show null observations (Fig. 3) consistent with their location close to the center of the upwelling. Stations HOT28 and KRO (Fig. 3) are not consistent with the proposed flow geometry being oriented NW-SE rather than SW-NE as we might expect for flow toward the Reykjanes asthenospheric channel.

The horizontal flow of material away from the upwelling axis is most likely confined to the upper few hundred kilometers given the different fast direction orientations between adjacent stations and a lack of back azimuth dependence at individual stations. Regional isotropic tomography models for Iceland [1] show upwelling material spreading out laterally beneath the Icelandic lithosphere and forming a layer $\sim 200 \mathrm{~km}$ thick. If the layer of anisotropy responsible for our splitting observations is $200 \mathrm{~km}$ thick it would need to have $4 \%$ anisotropy to generate splitting delays up to $2 \mathrm{~s}$ as we observed. This is consistent with the typical value of $4 \%$ anisotropy observed in natural peridotites from $\sim 150 \mathrm{~km}$ depth [42].
The systematic variations in the rare earth elements, minor elements, and isotopic ratios of basalts also suggest that material from the Icelandic upwelling flows down the Reykjanes and Kolbeinsey ridges [12-14,23]. Isotopic constraints as well as thermal anomalies suggest that the Icelandic upwelling influences $2400 \mathrm{~km}$ of the Mid-Atlantic Ridge [15], including the entire length of the Reykjanes Ridge and $\sim 600 \mathrm{~km}$ on the Kolbeinsey Ridge [12,14]. While the observed straightness of V-shaped ridges has been used to argue for channeled flow [19,21-23,26], Ito $[25,28]$ showed that radial flow can also predict Vshaped ridges and the only slight curvature expected would be difficult to discern given the relatively high velocity at which the upwelling material is expected to flow horizontally $(\sim 100 \mathrm{~mm} /$ year [22]) compared with the plate spreading rate $(\sim 10 \mathrm{~mm} /$ year $)$. We propose that the seismic anisotropy observations described here also supports the hypothesis that upwelling material is preferentially channeled down the adjacent mid-ocean ridges and are inconsistent with radial flow away from the upwelling.

Should our ridge-channeled model be appropriate, it is interesting to note that in some respects Iceland should be treated as an off-ridge hotspot. The proposed flow geometry is consistent with the predicted channeling of hotspot material to adjacent mid-ocean ridges from off-ridge hotspots [23,68-71]. Iceland is usually considered a ridge-centered hotspot; however, the short ridge-segment across Iceland $(\sim 350 \mathrm{~km}$ in length) is offset from the rest of the North Atlantic Ridge by $\sim 200 \mathrm{~km}$. The horizontal flow of upwelled material beneath Iceland therefore represents both a ridge-perpendicular channel feeding material back to the ridge, and subsequent flow of this material along the ridge in asthenospheric channels.

\section{Summary}

Shear-wave splitting observations across Iceland can be related to asthenospheric flow, providing constraints on the interactions of the Icelandic upwelling, the Mid-Atlantic Ridge and larger scale North Atlantic convection processes. Our splitting observations lead to the following conclusions regarding the anisotropic structure and flow beneath Iceland. 
1. The primary source of anisotropic signal as observed by teleseismic shear-wave arrivals is the upper mantle. Since crustal splitting times in Iceland are 0.1 to $0.3 \mathrm{~s}$, our delays of up to $2 \mathrm{~s}$ require a mantle source. Both the close proximity but dissimilarity of anisotropy observations for stations in western and central Iceland, and the insensitivity of inferred anisotropy to back-azimuth, require that the anisotropic structure is located in the upper mantle.

2. The anisotropic structure beneath Iceland is dominated by a single layer of anisotropy. First, the lack of dependence of the splitting parameters on event back azimuth suggests one-layer model. Second, the observations of null splits for events where the back azimuth is near-parallel or -perpendicular to the fast splitting directions (observed using other earthquakes) also indicate that one layer of anisotropy dominates.

3. While both high stress plus enriched water content and melt-rich layers can result in a $90^{\circ}$ rotation of the fast shear-wave splitting direction with respect to the flow direction, we expect the fast axis of shear-wave splits to be parallel to the flow direction beneath Iceland as the magnitude of stress is low and the amount and lateral extent of melt is likely small.

4. We hypothesize that the observed anisotropy pattern beneath Iceland represents ridge-channeled flow: horizontal flow of upwelling material toward and then along the North Atlantic Ridge. The splitting observations are consistent with flow from the upwelling axis to the southern end of the Kolbeinsey Ridge but are not consistent with radial flow of material away from the upwelling. We propose that upwelling material also flows to the northern end of the Reykjanes Ridge and that the V-shaped ridges to the north and south of Iceland are the product of this channeled flow along asthenospheric channels.

\section{Acknowledgments}

We thank Cecily J. Wolf and Paul G. Silver for their shear wave splitting codes, Greg Waite, Kristoffer T. Walker and Sebastien Chevrot for beneficial discussions. Helpful reviews were provided by
Rob van der Hilst, Garrett Ito, Cecily Wolfe and an anonymous reviewer. The IRIS DMC provided seismic data. The Graduate School of the University of Wisconsin-Madison, provided funding for M.X. and R.A. The figures were produced with SAC and GMT [72].

\section{References}

[1] R.M. Allen, G. Nolet, W.J. Morgan, K. Vogfjord, B.H. Bergsson, P. Erlendsson, G.R. Foulger, S. Jakobsdottir, B.R. Julian, M. Pritchard, S. Ragnarsson, R. Stefansson, Imaging the mantle beneath Iceland using integrated seismological techniques, J. Geophys. Res.-Solid Earth 107 (2002) 2325, doi:10.1029/2001JB000595.

[2] C.J. Wolfe, I.T. Bjarnason, J.C. VanDecar, S.C. Solomon, Seismic structure of the Iceland mantle plume, Nature 385 (1997) 245-247.

[3] R.M. Allen, G. Nolet, W.J. Morgan, K. Vogfjord, B.H. Bergsson, P. Erlendsson, G.R. Foulger, S. Jakobsdottir, B.R. Julian, M. Pritchard, S. Ragnarsson, R. Stefansson, The thin hot plume beneath Iceland, Geophys. J. Int. 137 (1999) 51-63.

[4] G.R. Foulger, M.J. Pritchard, B.R. Julian, J.R. Evans, R.M. Allen, G. Nolet, W.J. Morgan, B.H. Bergsson, P. Erlendsson, S. Jakobsdottir, S. Ragnarsson, R. Stefansson, K. Vogfjord, Seismic tomography shows that upwelling beneath Iceland is confined to the upper mantle, Geophys. J. Int. 146 (2001) $504-530$.

[5] R.C. Searle, J.A. Keeton, R.B. Owens, R.S. White, R. Mecklenburgh, B. Parsons, S.M. Lee, The Reykjanes Ridge: structure and tectonics of a hot-spot-influenced, slow-spreading ridge, from multibeam bathymetry, gravity and magnetic investigations, Earth Planet. Sci. Lett. 160 (1998) 463-478.

[6] R.E. Bell, W.R. Buck, Crustal control of ridge segmentation inferred from observations of the Reykjanes Ridge, Nature 357 (1992) 583-586.

[7] F.A. Darbyshire, R.S. White, K.F. Priestley, Structure of the crust and uppermost mantle of Iceland from a combined seismic and gravity study, Earth Planet. Sci. Lett. 181 (2000) 409-428.

[8] R.M. Allen, G. Nolet, W.J. Morgan, K. Vogfjord, M. Nettles, G. Ekstrom, B.H. Bergsson, P. Erlendsson, G.R. Foulger, S. Jakobsdottir, B.R. Julian, M. Pritchard, S. Ragnarsson, R. Stefansson, Plume-driven plumbing and crustal formation in Iceland, J. Geophys. Res.-Solid Earth 107 (2002) 2163, doi:10.1029/2001JB000584.

[9] M. Talwani, C.C. Windisch, J. Marcus, G. Langseth, Rekjanes ridge crest: a detailed geophysical study, J. Geophys. Res. 76 (1971) 473-517.

[10] P. Vogt, Asthenosphere motion recorded by the ocean floor south of Iceland, Earth Planet. Sci. Lett. 13 (1971) 153-160.

[11] S.M. Jones, N. White, J. Maclennan, V-shaped ridges around Iceland: implications for spatial and temporal patterns of 
mantle convection, Geochem. Geophys. Geosyst. 3 (2002) 1059, doi:10.1029/2002GC000361.

[12] J.-G. Schilling, Iceland mantle plume: geochemical study of Reykjanes ridge, Nature 242 (1973) 565-571.

[13] J.G. Schilling, R. Kingsley, D. Fontignie, R. Poreda, S. Xue, Dispersion of the Jan Mayen and Iceland mantle plumes in the Arctic: a $\mathrm{He}-\mathrm{Pb}-\mathrm{Nd}-\mathrm{Sr}$ isotope tracer study of basalts from the Kolbeinsey, Mohns, and Knipovich ridges, J. Geophys. Res.-Solid Earth 104 (1999) 10543-10569.

[14] R. Poreda, J.G. Schilling, H. Craig, Helium and hydrogen isotopes in ocean-ridge basalts north and south of Iceland, Earth Planet. Sci. Lett. 78 (1986) $1-17$.

[15] R.N. Taylor, M.F. Thirlwall, B.J. Murton, D.R. Hilton, M.A.M. Gee, Isotopic constraints on the influence of the Icelandic plume, Earth Planet. Sci. Lett. 148 (1997) E1-E8.

[16] J. Ritsema, R.M. Allen, The elusive mantle plume, Earth Planet. Sci. Lett. 207 (2003) 1-12.

[17] R. Montelli, G. Nolet, F.A. Dahlen, G. Masters, E.R. Engdahl, S.H. Hung, Finite-frequency tomography reveals a variety of plumes in the mantle, Science 303 (2004) $338-343$

[18] C. Megnin, B. Romanowicz, The three-dimensional shear velocity structure of the mantle from the inversion of body, surface and higher-mode waveforms, Geophys. J. Int. 143 (2000) 709-728.

[19] P.R. Vogt, Plume, subaxial pipe flow, and topography along the mid-ocean ridges, Earth Planet. Sci. Lett. 29 (1976) 309-325.

[20] M.G. Braun, R.A. Sohn, Melt migration in plume-ridge systems, Earth Planet. Sci. Lett. 213 (2003) 417-430.

[21] M.M. Yale, J.P. Morgan, Asthenosphere flow model of hotspot-ridge interactions: a comparison of Iceland and Kerguelen, Earth Planet. Sci. Lett. 161 (1998) 45-56.

[22] R.S. White, J.W. Bown, J.R. Smallwood, The temperature of the Iceland plume and origin of outward-propagating Vshaped ridges, J. Geol. Soc. 152 (1995) 1039-1045.

[23] J.G. Schilling, Upper mantle heterogeneities and dynamics, Nature 314 (1985) 62-67.

[24] G. Ito, Y. Shen, G. Hirth, C.J. Wolfe, Mantle flow, melting, and dehydration of the Iceland mantle plume, Earth Planet. Sci. Lett. 165 (1999) 81-96.

[25] G. Ito, Reykjanes ' $V$ '-shaped ridges originating from a pulsing and dehydrating mantle plume, Nature 411 (2001) 681-684.

[26] M. Albers, U.R. Christensen, Channeling of plume flow beneath mid-ocean ridges, Earth Planet. Sci. Lett. 187 (2001) 207-220.

[27] G. Ito, J. Lin, D. Graham, Observational and theoretical studies of the dynamics of mantle plume-mid-ocean ridge interaction, Rev. Geophys. 41 (2003).

[28] G. Ito, J. Lin, C.W. Gable, Dynamics of mantle flow and melting at a ridge-centered hotspot: Iceland and the MidAtlantic ridge, Earth Planet. Sci. Lett. 144 (1996) 53-74.

[29] N. White, B. Lovell, Measuring the pulse of a plume with the sedimentary record, Nature 387 (1997) 888-891.

[30] I.T. Bjarnason, P.G. Silver, G. Rumpker, S.C. Solomon, Shear wave splitting across the Iceland hot spot: results from the
ICEMELT experiment, J. Geophys. Res.-Solid Earth 107 (2002) 2382, doi:10.1029/2001JB000916.

[31] A.B. Li, R.S. Detrick, Azimuthal anisotropy and phase velocity beneath Iceland: implication for plume-ridge interaction, Earth Planet. Sci. Lett. 214 (2003) 153-165.

[32] R. Stefansson, R. Bodvarsson, R. Slunga, P. Einarsson, S. Jakobsdottir, H. Bungum, S. Gregersen, J. Havskov, J. Hjelme, H. Korhonen, Earthquake prediction research in the South Iceland seismic zone and the Sil Project, Bull. Seismol. Soc. Am. 83 (1993) 696-716.

[33] P.G. Silver, W.W. Chan, Implications for continental structure and evolution from seismic anisotropy, Nature 335 (1988) $34-39$.

[34] P.G. Silver, W.W. Chan, Shear-wave splitting and subcontinental mantle deformation, J. Geophys. Res.-Solid Earth 96 (1991) 16429-16454.

[35] C.J. Wolfe, P.G. Silver, Seismic anisotropy of oceanic upper mantle: shear wave splitting methodologies and observations, J. Geophys. Res.-Solid Earth 103 (1998) 2791.

[36] M.K. Savage, Seismic anisotropy and mantle deformation: what have we learned from shear wave splitting? Rev. Geophys. 37 (1999) 65-106.

[37] S. Pilidou, K. Priestley, E. Debayle, O. Gudmundsson, Rayleigh wave tomography in the North Atlantic: high resolution images of the Iceland, Azores and Eifel mantle plumes, Lithos 79 (2005) 453-474.

[38] P.G. Silver, Seismic anisotropy beneath the continents: probing the depths of geology, Annu. Rev. Earth Planet. Sci. 24 (1996) 385-432.

[39] W. Menke, B. Brandsdottir, S. Jakobsdottir, R. Stefansson, Seismic anisotropy in the crust at the Mid-Atlantic plate boundary in South-West Iceland, Geophys. J. Int. 119 (1994) 783-790.

[40] N. Favier, S. Chevrot, Sensitivity kernels for shear wave splitting in transverse isotropic media, Geophys. J. Int. 153 (2003) 213-228.

[41] R.L. Saltzer, J.B. Gaherty, T.H. Jordan, How are vertical shear wave splitting measurements affected by variations in the orientation of azimuthal anisotropy with depth? Geophys. J. Int. 141 (2000) 374-390.

[42] D. Mainprice, P.G. Silver, Interpretation of Sks-waves using samples from the subcontinental lithosphere, Phys. Earth Planet. Inter. 78 (1993) 257-280.

[43] N.M. Ribe, Y. Yu, A theory for plastic-deformation and textural evolution of olivine polycrystals, J. Geophys. Res.Solid Earth Planets 96 (1991) 8325-8335.

[44] D.M. Parks, S. Ahzi, Polycrystalline plastic-deformation and texture evolution for crystals lacking 5 independent slip systems, J. Mech. Phys. Solids 38 (1990) $701-724$.

[45] A. Nicolas, F. Boudier, A.M. Boullier, Mechanisms of flow in naturally and experimentally deformed peridotites, Am. J. Sci. 273 (1973) 853-876.

[46] Y. Ida, Preferred orientation of olivine and anisotropy of the oceanic lithosphere, J. Phys. Earth 32 (1984) 245-257.

[47] H.R. Wenk, K. Bennett, G.R. Canova, A. Molinari, Modeling plastic-deformation of peridotite with the self-consistent 
theory, J. Geophys. Res.-Solid Earth Planets 96 (1991) 8337-8349.

[48] S.Q. Zhang, S. Karato, Lattice preferred orientation of olivine aggregates deformed in simple shear, Nature 375 (1995) $774-777$.

[49] H. Jung, S. Karato, Water-induced fabric transitions in olivine, Science 293 (2001) 1460-1463.

[50] B.K. Holtzman, D.L. Kohlstedt, M.E. Zimmerman, F. Heidelbach, T. Hiraga, J. Hustoft, Melt segregation and strain partitioning: implications for seismic anisotropy and mantle flow, Science 301 (2003) 1227-1230.

[51] M. Bystricky, K. Kunze, L. Burlini, J.P. Burg, High shear strain of olivine aggregates: rheological and seismic consequences, Science 290 (2000) 1564-1567.

[52] E. Kaminski, The influence of water on the development of lattice preferred orientation in olivine aggregates, Geophys. Res. Lett. 29 (2002), doi:10.1029/2002GL014710.

[53] J.G. Schilling, M. Zajac, R. Evans, T. Johnston, W. White, J.D. Devine, R. Kingsley, Petrologic and geochemical variations along the Mid-Atlantic ridge from 29-Degrees-N to 73Degrees-N, Am. J. Sci. 283 (1983) 510-586.

[54] N. Metrich, H. Sigurdsson, P.S. Meyer, J.D. Devine, The 1783 Lakagigar eruption in Iceland-geochemistry, $\mathrm{CO}_{2}$ and sulfur degassing, Contrib. Mineral. Petrol. 107 (1991) $435-447$.

[55] C.D. Byers, M.O. Garcia, D.W. Muenow, Volatiles in basaltic glasses from the East Pacific Rise at 21-Degrees-N-implications for morb sources and submarine lava flow morphology, Earth Planet. Sci. Lett. 79 (1986) 9-20.

[56] A.R.L. Nichols, M.R. Carroll, A. Hoskuldsson, Is the Iceland hot spot also wet? Evidence from the water contents of undegassed submarine and subglacial pillow basalts, Earth Planet. Sci. Lett. 202 (2002) 77-87.

[57] J.-C.C. Mercier, Magnitude of the continental lithospheric stresses infered from rheomorphic petrology, J. Geophys. Res. 85 (1980) 6293-6303.

[58] R.K. Staples, R.S. White, B. Brandsdottir, W. Menke, P.K.H. Maguire, J.H. McBride, Faroe-Iceland Ridge Experiment: 1. Crustal structure of northeastern Iceland, J. Geophys. Res.Solid Earth 102 (1997) 7849-7866.

[59] D. McKenzie, Constraints on melt generation and transport from U-series activity ratios, Chem. Geol. 162 (2000) 81-94.
[60] H. Nicholson, D. Latin, Olivine Tholeiites from Krafla, Iceland - evidence for variations in melt fraction within a plume, J. Petrol. 33 (1992) 1105-1124.

[61] R.S. White, D. McKenzie, Mantle plumes and flood basalts, J. Geophys. Res.-Solid Earth 100 (1995) 17543-17585.

[62] L. Slater, D. McKenzie, K. Gronvold, N. Shimizu, Melt generation and movement beneath Theistareykir, NE Iceland, J. Petrol. 42 (2001) 321-354.

[63] J. Maclennan, D. McKenzie, K. Gronvold, Plume-driven upwelling under central Iceland, Earth Planet. Sci. Lett. 194 (2001) 67-82.

[64] D.K. Blackman, J.M. Kendall, P.R. Dawson, H.R. Wenk, D. Boyce, J.P. Morgan, Teleseismic imaging of subaxial flow at mid-ocean ridges: traveltime effects of anisotropic mineral texture in the mantle, Geophys. J. Int. 127 (1996) $415-426$

[65] C.J. Wolfe, S.C. Solomon, Shear-wave splitting and implications for mantle flow beneath the MELT region of the East Pacific Rise, Science 280 (1998) 1230-1232.

[66] D.W. Forsyth, S.C. Webb, L.M. Dorman, Y. Shen, Phase velocities of Rayleigh waves in the MELT experiment on the East Pacific Rise, Science 280 (1998) $1235-1238$.

[67] A.E. Gripp, R.G. Gordon, Current plate velocities relative to the hotspots incorporating the Nuvel-1 global plate motion model, Geophys. Res. Lett. 17 (1990) 1109-1112.

[68] C. Kincaid, J.G. Schilling, C. Gable, The dynamics of offaxis plume-ridge interaction in the uppermost mantle, Earth Planet. Sci. Lett. 137 (1996) 29-43.

[69] R.H. Kingsley, J.G. Schilling, Plume-ridge interaction in the Easter Salas y Gomez seamount chain Easter Microplate system: Pb isotope evidence, J. Geophys. Res.-Solid Earth 103 (1998) 24159-24177.

[70] C. Small, Observations of ridge-hotspot interactions in the southern-ocean, J. Geophys. Res.-Solid Earth 100 (1995) $17931-17946$.

[71] C. Kincaid, G. Ito, C. Gable, Laboratory investigation of the interaction of off-axis mantle plumes and spreading Centers, Nature 376 (1995) 758-761.

[72] P. Wessel, W.H.F. Smith, New version of the generic mapping tools released, EOS Trans. Am. Geophys. Union 76 (1995) 329 